\title{
CFD Study of Thermal Comfort in Urban Area
}

\author{
Fidaros Dimitris ${ }^{1, *}$, Baxevanou Catherine ${ }^{1}$, Tsagrasoulis Aris $^{2}$, Bartzanas Thomas $^{1}$, Kittas Constantinos $^{3}$ \\ ${ }^{1}$ Center for Research and Technology, Hellas- Institute for Research and Technology, Greece \\ ${ }^{2}$ Department of Architecture, Polytechnic School, University of Thessaly, Greece \\ ${ }^{3}$ Department of Agriculture Crop Production and Rural Environment, School of Agricultural Sciences, University of Thessaly, Greece
}

Copyright $\bigcirc 2017$ by authors, all rights reserved. Authors agree that this article remains permanently open access under the terms of the Creative Commons Attribution License 4.0 International License

\begin{abstract}
The reduction of energy consumption for cooling should be addressed on a city level since the urban environment where the building operates increases its cooling needs and deteriorates the heat pumps operation. In the present work, a Computational Fluid Dynamics (CFD) model is used to study the improvement of microclimate conditions in an urban agglomeration of the city of Volos, through bioclimatic interventions. The Boussinesq approximation is used in order to take into account the thermal buoyancy while the Discrete Ordinate (DO) model is used for the radiation transport. The ground temperature is calculated by solving an energy balance model while the ground is also considered an infrared diffusive radiation emitter. The planted surfaces are considered finite thickness heat sinks and the roofs and building walls are also took as finite thickness isothermal walls and heat sources (the heat pumps and electrical device operation, lighting and, residences presence). Trees are regarded as porous volumes. The surfaces of water elements are considered isothermal heat sink walls. The local microclimate before and after the bioclimatic interventions is presented by comparing the temperature and wind speed distributions as well as the thermal comfort indices for a typical summer day.
\end{abstract}

Keywords CFD, Urban Environment, Thermal Comfort, Radiation, Bioclimatic Intervention

\section{Introduction}

In the past, energy in buildings was consumed mainly for heating but today is also consumed to a high degree for cooling. This increase is due to: a) the development and widespread use of the cooling technology, b) the deterioration of the urban environment. Dense construction and lack of greenery are responsible for the development of the urban heat island. The reduction in energy consumption for heating can be dealt with on a building level, but the case of energy reduction for cooling should be dealt with on a city or neighborhood level. And this is because the urban environment, where a building operates, burdens considerably its cooling needs and the operation of the used heat pumps. The study of the microclimate developed in the urban core is a multivariate problem since the formation of the final pressure, air speed, temperature and humidity field depend upon factor such as: a) local climatic conditions, b) geometry and orientation of buildings, streets and openings, c) used materials in buildings, streets and public spaces, d) existence of greenery and water elements, e) the produced heat in buildings due to residents presence, device operation, lights and heat pumps etc.

One way to describe this complex problem is through field measurements. However those measurements give information about specific points and require a large number of assumptions to be adopted in order to draw conclusions for a whole region. Nevertheless this does not reduce their value and the information they provide. Furthermore, those measurements can be used for validation of produced numerical models for the description of the developed microclimate $[1,2]$. Measurement techniques are also used by numerical models for the preparation of the urban space computational grid [3].

The methods of Computational Fluid Dynamics (CFD), is another modern way to simulate the developed transport phenomena and to determine the urban microclimate behavior. Those methods can offer a full depiction of the developed microclimate in an area and even consider improvement scenarios by using appropriate materials, adding water elements and green areas, shaping public spaces etc. In this context, the flow field developed in an urban core was studied with CFD without taking into account the energy but focusing on the study of wind and turbulence modelling in paper [2]. A combination of measurements, CFD calculations for the flow aerodynamic and TRNSYS software for the thermodynamics are used in [4] in order to study bioclimatic measures aiming in the rehabilitation of specific open spaces in Tirana during winter and summer. The concept of different techniques coupling is also used in [5] where a CFD model is used for convective heat, air and vapor transfer with a Building Envelope Heat and Moisture (BE-HAM) model and a radiation model (RAD) for the study 
of the microclimate of urban heat island effect in an urban street canyon. In the paper [6] also a CFD model was developed for the description of the urban microclimate considering the heat transfer through an energy balance model (EBM) for the definition of the boundary conditions but without direct simulation of the radiative transport equation (RTE). In another developed model [7], the buildings are described as sources of heat and radiation estimating the contribution of urban planting to the reduction of the air temperature in the urban environment. Another CFD model was also developed for the greenery and water elements simulation as sinks in the momentum and energy equations [8]. Since a number of individual models describing the effect of several factors on the microclimate were developed [9], CFD codes that combine some of these models were used for the study of real urban segments (eg Athens [10], Florina [11]) in order to study methods for mitigation of the urban heat island effect.

In the present work a CFD model was developed for the study of transport phenomena in the urban core of the city of Volos. An EBM was used for the description of buildings, streets, greenery and water elements as sources or sinks of heat. The greenery is simulated as porous material, while the radiation equation is solved directly for two wave length bands (solar radiation with $\lambda=0-0.76 \mu \mathrm{m}$ and thermal radiation with $\lambda=0.76-100 \mu \mathrm{m}$ ). This model was used for the description of the current microclimate in the studied area and for the prediction of the microclimate evolution after an integrated intervention during a typical summer day when the urban heat island effect is most intensive.

\section{Methodology}

\subsection{Mathematical Model}

The flow field and the transport phenomena developed in the computational domain are described by the Reynolds Averaged Navier-Stokes equations [12, 13]. The continuity, momentum and energy conservation equations are solved in $3 \mathrm{D}(\mathrm{x}, \mathrm{y}, \mathrm{z})$, as well as the equations that correspond to the turbulent model. The flow is considered $3 \mathrm{D}$, steady state, incompressible and turbulent. The turbulence effect in the developed flow and heat transfer is modeled through the standard k- $\varepsilon$ high Reynolds model [14]. The effect of thermal buoyancy is modeled using the Boussinesq approximation. The radiation is modeled using the Discrete Ordinate (DO) model $[15,16]$. The radiation transfer equations are solved in two wave length bands, one corresponding to the solar radiation (short wave with $\lambda=0-0.76 \mu \mathrm{m}$ ) and one corresponding to the thermal radiation (long wave $\lambda=0.76$ $100 \mu \mathrm{m})$. The greenery is considered porous materials that cause pressure drop and further more a heat sink. In the momentum conservation equations two source terms are added: one corresponds to thermal buoyancy and the other corresponds to the pressure drop inside the porous media.
[17].

$$
S_{U_{i}}=-\frac{\rho_{\text {air }} \cdot C_{D} \cdot L A D \cdot u_{i} \bar{u}}{2}
$$

Where, $\mathrm{S}_{\mathrm{Ui}}$ is the sink term in the i-direction of the momentum conservation equation, $\left(C_{D}=0.2\right)$ the drag coefficient, $(\mathrm{LAD}=7)$ the leaf area density, $\mathrm{u}_{\mathrm{i}}$ the local speed in the i-direction and, $\bar{u}$ the magnitude of local speed.

In the energy equation are added:

a) a source term corresponding to the thermal radiation calculated by the DO model,

b) a source term corresponding to the heat produced by buildings,

c) a sink term that corresponds to the air temperature reduction due to evapotranspiration of greenery and

d) a sink term that corresponds to temperature reduction due to evaporation of water elements.

The heat is produced by buildings and comes from:

a) the resident's presence,

b) the operation of the domestic equipment,

c) the heat produced by lights operation

d) the heat rejected by heat pumps.

Taking into account the above an average heat production is considered to be $28 \mathrm{~W} / \mathrm{m}^{2}$. According to FAO instructions [18], the average evapotranspiration rate (ETc) for trees in the Mediterranean area with low humidity is 6-9 $\mathrm{mm}$ /day for temperatures higher than $30 \mathrm{o}$ C. If an average value is taken into account this leads to a heat consumption of $212 \mathrm{~W} / \mathrm{m}^{2}$. The final heat consumption depends on the trees' leaf area index (LAI). This is considered to have an average value of 3.

The water element surface is considered an isothermal wall with a temperature of $25^{\circ} \mathrm{C}$, as well as a heat sink due to water evaporation. For a typical summer day with an average temperature of $33^{\circ} \mathrm{C}$ and a relative humidity of $47 \%$ this leads to a heat sink of $200 \mathrm{~W} / \mathrm{m}^{2}$. Finally to the turbulence models' equations are added the following source terms due to greenery elements [17].

$$
\begin{aligned}
& S_{k}=-\rho_{\text {air }} \cdot C_{D} \cdot L A D \cdot \bar{u}^{3} \\
& S_{\varepsilon}=\frac{\varepsilon}{k} \cdot \rho_{a i r} \cdot C_{D} \cdot L A D \cdot \bar{u}^{3}
\end{aligned}
$$

Where, $S_{\mathrm{k}}$ the sink term of the turbulence kinetic energy equation and $\mathrm{S}_{\varepsilon}$ the sink term of the turbulent dissipation.

\subsection{Numerical Model}

The finite volume method is used for the resolve of the 3D Navier Stokes partial differential equations [13] using the OpenFOAM software. A hybrid multiblock grid of 6538192 cells was used, created by 22 blocks. The discretized continuity and momentum equations are coupled using the SIMPLE algorithm [12]. Due to the fact that in the solid boundaries wall functions are used, the grid is formed 
securing that the nondimensional distance $\mathrm{y}_{+}$is between 10 and 40 . The diffusion terms are discretized using central differences while for the discretization of the convection terms $2^{\text {nd }}$ order upwind scheme are used. The absolute convergence criteria for the momentum, pressure and concentration equations are set to $\mathrm{e}=10^{-5}$ and for the energy and radiation is set to $\mathrm{e}=10^{-6}$.

\section{Case Study}

\subsection{Geometry}

In Figure 1, the geometry of the simulation domain is given. In order to avoid side effect in the simulation results, the computational domain boundaries are expanded by $8 \mathrm{H}$ from the interest area and $6 \mathrm{H}$ vertically over the buildings surface $(H$, is the buildings height) $[14,17]$. This way all the lateral sides can be used either as inlet or outlet surfaces given that during a day the wind direction varies.

\subsection{Boundary Conditions}

Depending on the time of the day, 3 of the lateral sides are considered inlet boundary conditions (known values of air velocity components, $u_{i}$, turbulent kinetic energy, $k$, dissipation rate, $\varepsilon$, and air temperature T).The same boundary condition is set to the upper boundary. On the surface from which the air is expected to leave the simulation domain, a pressure outlet condition is set (known pressure equal to the atmospheric).

The streets, the sidewalks, the school courtyard as well as the under trees surfaces are modeled as isothermal walls. This corresponds to no-slip and no penetration boundaries for momentum equations while as far as the energy equation is concerned a predefined value of temperature is set. Concerning the radiation transport equation those surfaces are considered to emit thermal diffusive radiation according to their temperature, material and color.

The low planting surfaces are regarded as finite thickness walls and heat sinks due to evapotranspiration. The building's roofs and side walls are also considered isothermal walls with finite thickness. Inside this finite thickness it is assumed that the heat due to residents' activation, devices, lights and heat pumps operation is produced. The trees are considered porous volumes working as source and sink terms in the momentum, turbulence and energy equations. Finally, the water element surface is also considered to be an isothermal wall and heat sink. The wind speed in the boundary inlet is assumed to follow an exponential distribution profile up to $11 \mathrm{~m}$ and above that a logarithmic one. So the wind speed components are given according to the following relationships [19].

$$
\begin{gathered}
z \leq 11 \quad u_{i}(z)=u_{i}\left(\frac{z}{z_{\text {ref }}}\right)^{a} \\
z>11 \quad u_{i}(z)=\frac{u_{*}}{\kappa} \cdot \ln \left(\frac{z}{z_{0}}\right)
\end{gathered}
$$

Where $\mathrm{u}_{\mathrm{i}}$, the i-component of the wind speed on the level $\mathrm{z}$, $z_{\text {ref }}$ the reference height, $\alpha$ the exponent that takes into account the ground roughness, (for an urban environment $0.4), \kappa=0.35$, the von-Karman constant, $u^{*}$, the friction velocity and $\mathrm{z}_{0}$ the ground roughness height which is taken as a unit for the urban environment.

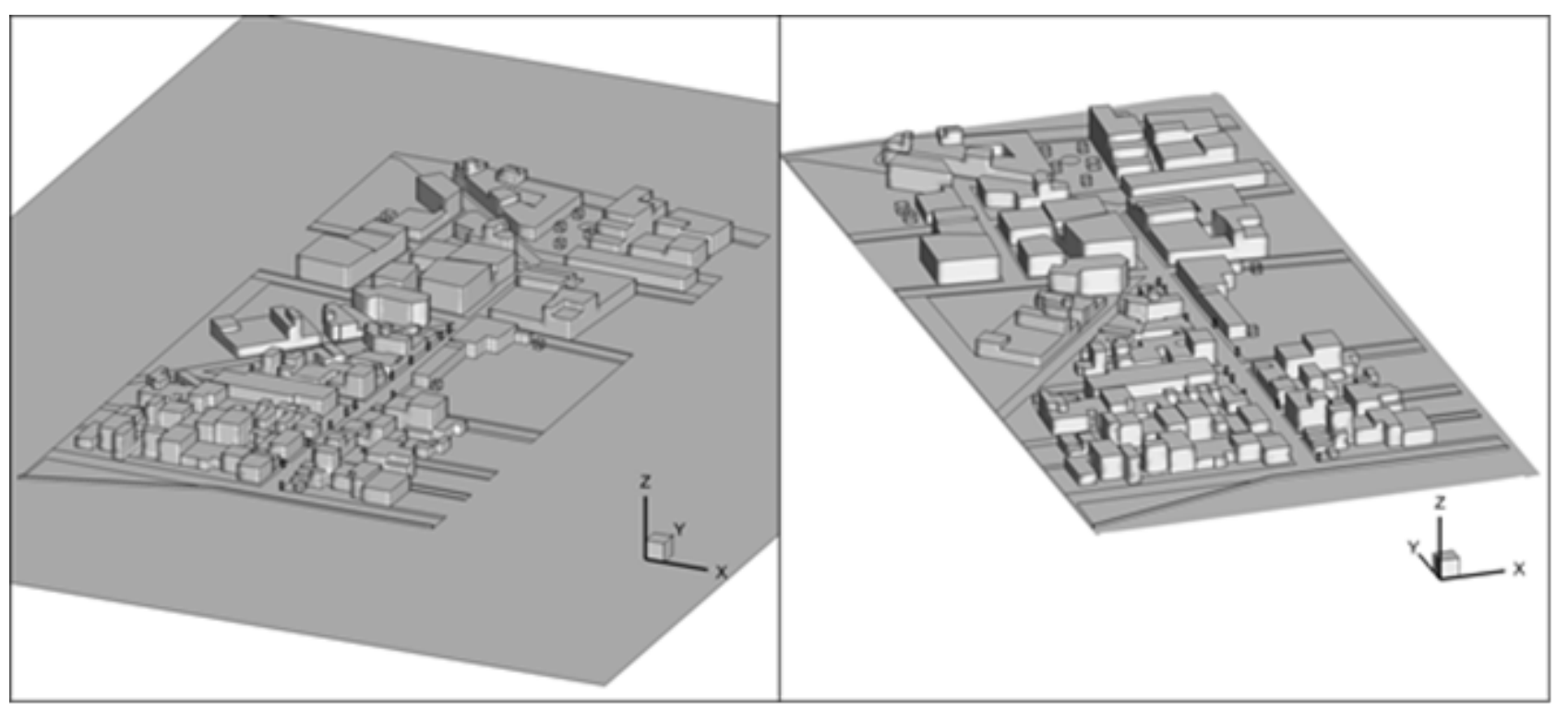

Figure 1. Geometry of the simulation domain 
The values of turbulent kinetic energy, $\mathrm{k}$, and of the dissipation rate, $\varepsilon$, are calculated for the inlet boundary conditions with the following relationships $[17,8]$.

$$
\begin{gathered}
k_{i n}=0.003 \cdot u_{i}^{3} \\
\varepsilon_{i n}=\left(C_{\mu}^{0,75} \cdot k_{i n}^{0.666}\right) \cdot(\kappa \cdot z)^{-1} \quad\left[C_{\mu}=0.09\right]
\end{gathered}
$$

The temperature of the ground, which acts as an isothermal wall, for every considered cover material is calculated for each simulated hour using an energy balance model $[6,8]$ taking into consideration the incident solar radiation, the air temperature, the underground temperature (in a depth of $15 \mathrm{~cm}$ ), the thermal conductivity of the material, the absorption coefficient in the solar radiation band and the emission coefficient in the thermal radiation band. This way in the definition of the surface temperature the temperature rise due to incident solar radiation, the heat transfer to and from the ground through conduction, the heat exchange with the environment due to convection and the thermal radiation exchange with the sky are taken into account. The radiation exchange with the rest surfaces of the computational domain is modeled through the DO model. The incident solar radiation on every solid and porous surface of the computational domain is calculated according to the inclination and orientation of each surface taking shading into account [20].

The buildings' roofs are deemed to have a thickness of $15 \mathrm{~cm}$ while the lateral walls have a thickness of $25 \mathrm{~cm}$. The buildings internal temperature used in the EBM was $28^{\circ} \mathrm{C}$. As far as the temperature of the lateral surface is concerned, two types are considered: a) glass surface, b) light color masonry and finally a weighted average value is calculated.

\subsection{Material Properties}

Surfaces corresponding to lateral walls according to their material are divided into masonry and glazing. The thermophysical properties of these materials are given in the following table.

Table 1. Thermophysical properties of lateral walls material

\begin{tabular}{|c|c|c|c|}
\hline & $\begin{array}{c}\text { Density, } \\
\boldsymbol{\rho}\left[\mathbf{k g} / \mathbf{m}^{3}\right]\end{array}$ & $\begin{array}{c}\text { Specific heat } \\
\text { capacity Cp } \\
{[\mathbf{k J} /(\mathbf{k g K})]}\end{array}$ & $\begin{array}{c}\text { Thermal } \\
\text { conductivity, } \mathbf{k} \\
{[\mathbf{W} /(\mathbf{m K})]}\end{array}$ \\
\hline Masonry & 1084 & 1.135 & 0.17 \\
\hline Glazing & 923 & 2.300 & 0.39 \\
\hline
\end{tabular}

Assuming that $25 \%$ of the lateral walls area is covered by glazing, the weighted average values are calculated for all thermophysical properties. In Table 2, the thermophysical properties for the used materials are presented. For trees and greenery the assuming porosity is set to $40 \%$. The air dynamic viscosity is $\mu=1.789 \times 10^{-5}$ (Pas) and the thermal expansion coefficient is $\beta=0.00343$. The optical properties of the materials are given in Table 3.

Table 2. Thermophysical properties of all used material

\begin{tabular}{|c|c|c|c|}
\hline & $\begin{array}{c}\text { Density, } \rho \\
{\left[\mathbf{k g} / \mathbf{m}^{3}\right]}\end{array}$ & $\begin{array}{c}\text { Specific heat } \\
\text { capacity Cp } \\
{[\mathbf{k J} /(\mathbf{k g K})]}\end{array}$ & $\begin{array}{c}\text { Thermal } \\
\text { conductivity, } \mathbf{k} \\
{[\mathbf{W} /(\mathbf{m K})]}\end{array}$ \\
\hline Ground & 946 & 1.920 & 0.35 \\
\hline $\begin{array}{c}\text { Roofs \& } \\
\text { shelters }\end{array}$ & 950 & 0.910 & 0.24 \\
\hline Lateral walls & 1021 & 1.590 & 0.26 \\
\hline Greenery & 700 & 2.310 & 0.173 \\
\hline Air & 1.225 & 1.005 & 0.0242 \\
\hline
\end{tabular}

Table 3. Optical properties of materials

\begin{tabular}{|c|c|c|c|c|c|c|}
\hline & \multicolumn{2}{|c|}{$\begin{array}{c}\text { Absorption } \\
\text { coefficient, } \boldsymbol{\alpha}[-]\end{array}$} & \multicolumn{2}{c|}{$\begin{array}{c}\text { Reflection } \\
\text { coefficient, } \boldsymbol{\rho}[-]\end{array}$} & \multicolumn{2}{c|}{$\begin{array}{c}\text { Emission } \\
\text { coefficient, } \boldsymbol{\varepsilon}[-]\end{array}$} \\
\cline { 2 - 7 } & SR & NIR & SR & NIR & SR & NIR \\
\hline Asphalt & 1 & 1 & 0 & 0 & 0.9 & 0.9 \\
\hline Pavement & 0.9 & 0.9 & 0.1 & 0.1 & 0.9 & 0.9 \\
\hline Grey roofs & 0.9 & 0.9 & 0.1 & 0.1 & 0.9 & 0.9 \\
\hline $\begin{array}{c}\text { Red } \\
\text { shelters }\end{array}$ & 0.6 & 0.6 & 0.4 & 0.4 & 0.8 & 0.8 \\
\hline Masonry & 0.3 & 0.3 & 0.7 & 0.7 & 0.9 & 0.9 \\
\hline Glazing & 0.05 & 0.1 & 0.06 & 0.06 & 0.9 & 0.9 \\
\hline Greenery & 0.8 & 0.2 & 0.2 & 0.8 & $0 . .975$ & 0.975 \\
\hline
\end{tabular}

\subsection{Parametric Study}

The object of the study is an area in the urban core of Volos, a segment of the quarter named 'Palia' close to the harbor with stigma $\left(\varphi=39^{\circ} 21.65^{\prime}, \mathrm{L}=22^{\circ} 56.15^{\prime}\right.$ ' and elevation of $3 \mathrm{~m}$ ). In this area exist:

i) public and private buildings of 2 or 3 stores,

ii) a school courtyard covered by asphalt,

iii) a few trees,

iv) pedestrian walkways covered by dark color tiles,

v) streets covered by common asphalt and

vi) a square covered with dark tiles and cement, sparse trees and a small fountain.

The area was studied for a typical summer day. For this day steady state simulations were conducted every 1 hour, with the following climatic data.

The examined area is $54000 \mathrm{~m}^{2}$ of which $25000 \mathrm{~m}^{2}$ are covered by buildings. The interventions are summarized as following: a) replace $12 \%$ of streets and pavements with tiles characterized by favorable optical properties, b) replace $1.6 \%$ of the streets with cold asphalt, c) addition trees to 100 $\mathrm{m}^{2}$ which also increase shading. In Table 5, the optical properties of the proposed materials are presented. 
Table 4. Climatic data of a typical summer day

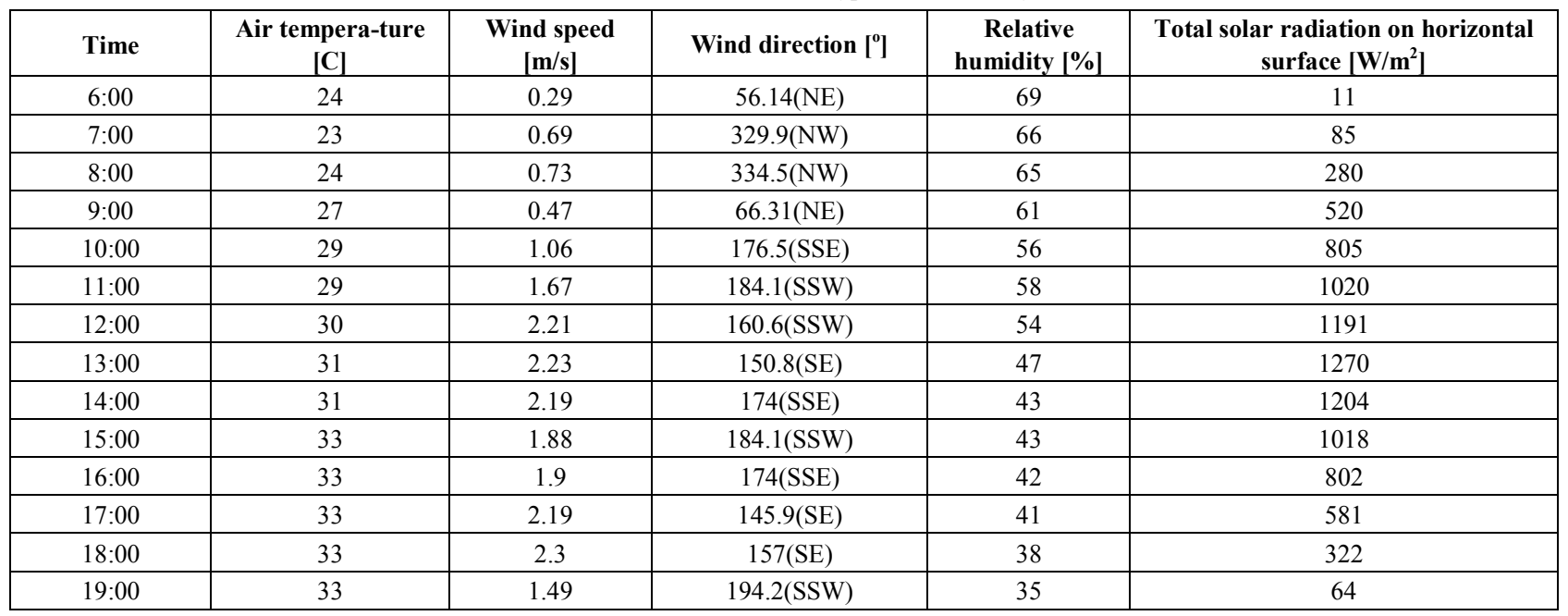

Table 5. Optical properties of the proposed materials

\begin{tabular}{|c|c|c|c|c|c|c|}
\hline & \multicolumn{2}{|c|}{ Absorption coefficient, $\boldsymbol{\alpha}[-]$} & \multicolumn{2}{c|}{ Reflection coefficient, $\boldsymbol{\rho}[-]$} & \multicolumn{2}{c|}{ Emission coefficient, $\boldsymbol{\varepsilon}[-]$} \\
\cline { 2 - 6 } & SR & NIR & SR & 0.66 & 0.9 \\
\hline Cold asphalt & 0.42 & 0.34 & 0.58 & 0.1 & 0.9 \\
\hline Cold tiles & 0.35 & 0.9 & 0.65 & 0.9 & 0.8 \\
\hline
\end{tabular}

\section{Results}

In Figures 2 to 4 the temperature distribution before and after the proposed intervention at $1.8 \mathrm{~m}$ is given for the hours 6:00, $12: 00$ and $16: 00$ of the typical day.

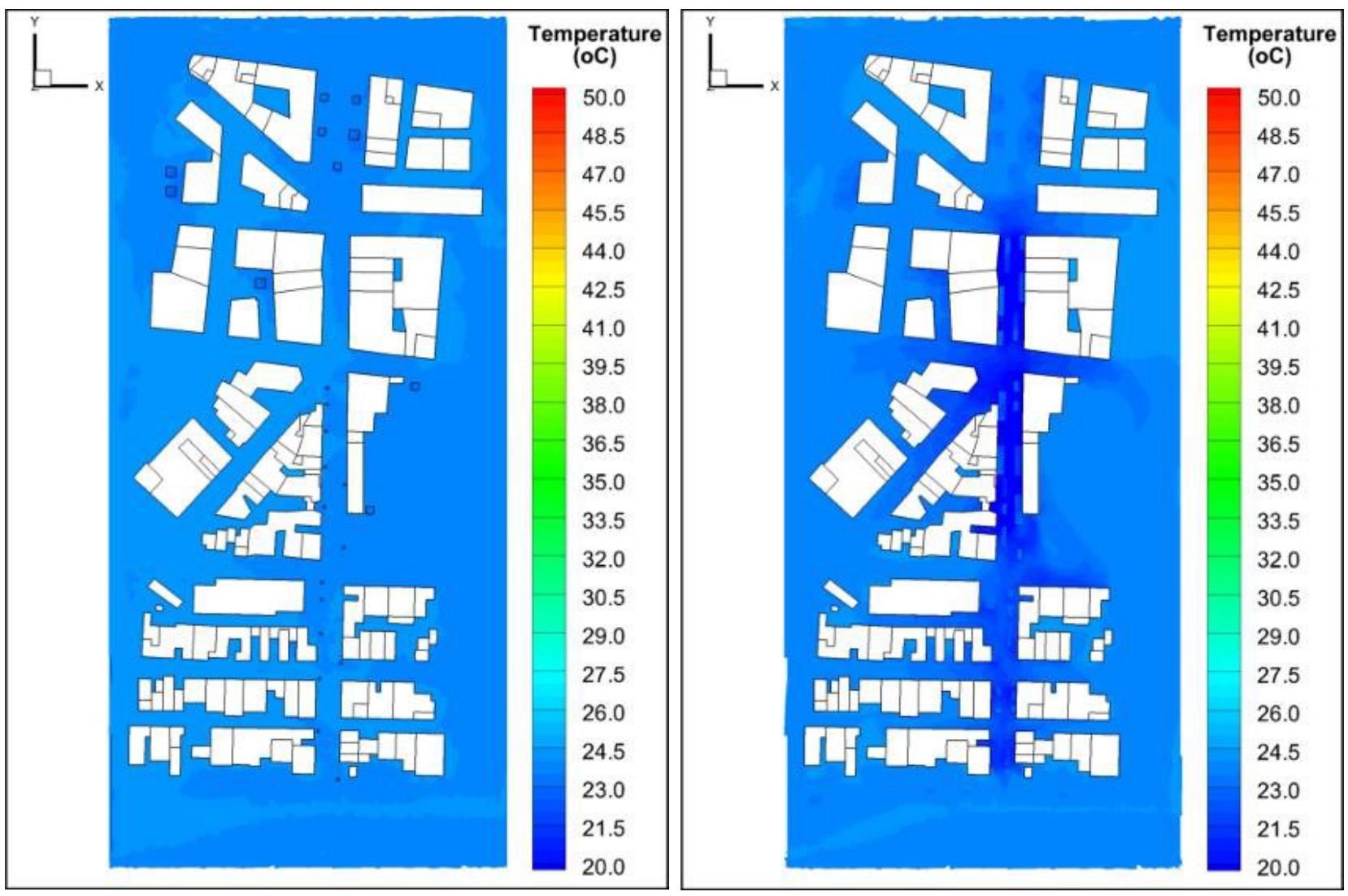

Figure 2. Temperature distribution before and after intervention at 6:00 


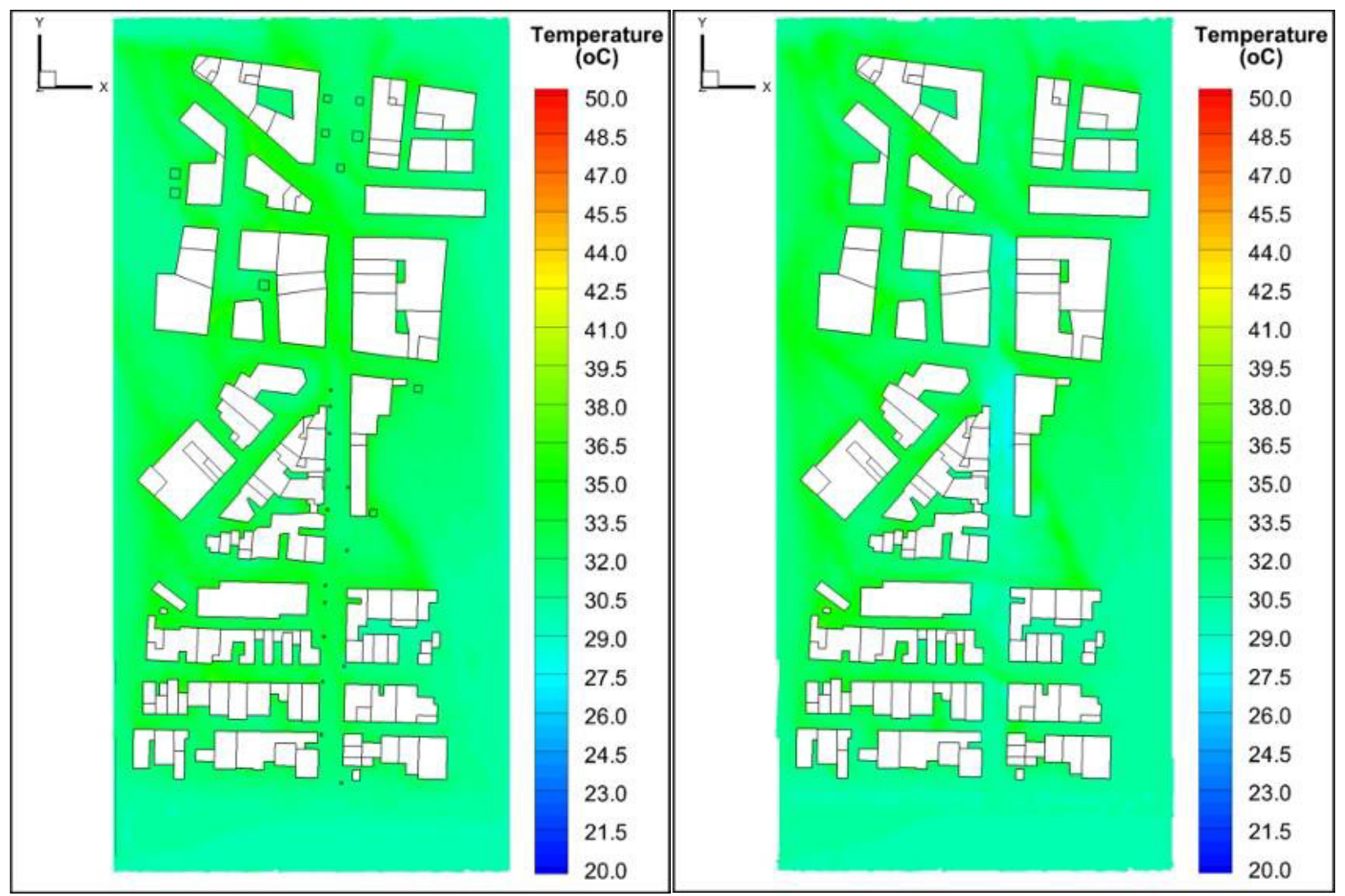

Figure 3. Temperature distribution before and after intervention at 12:00

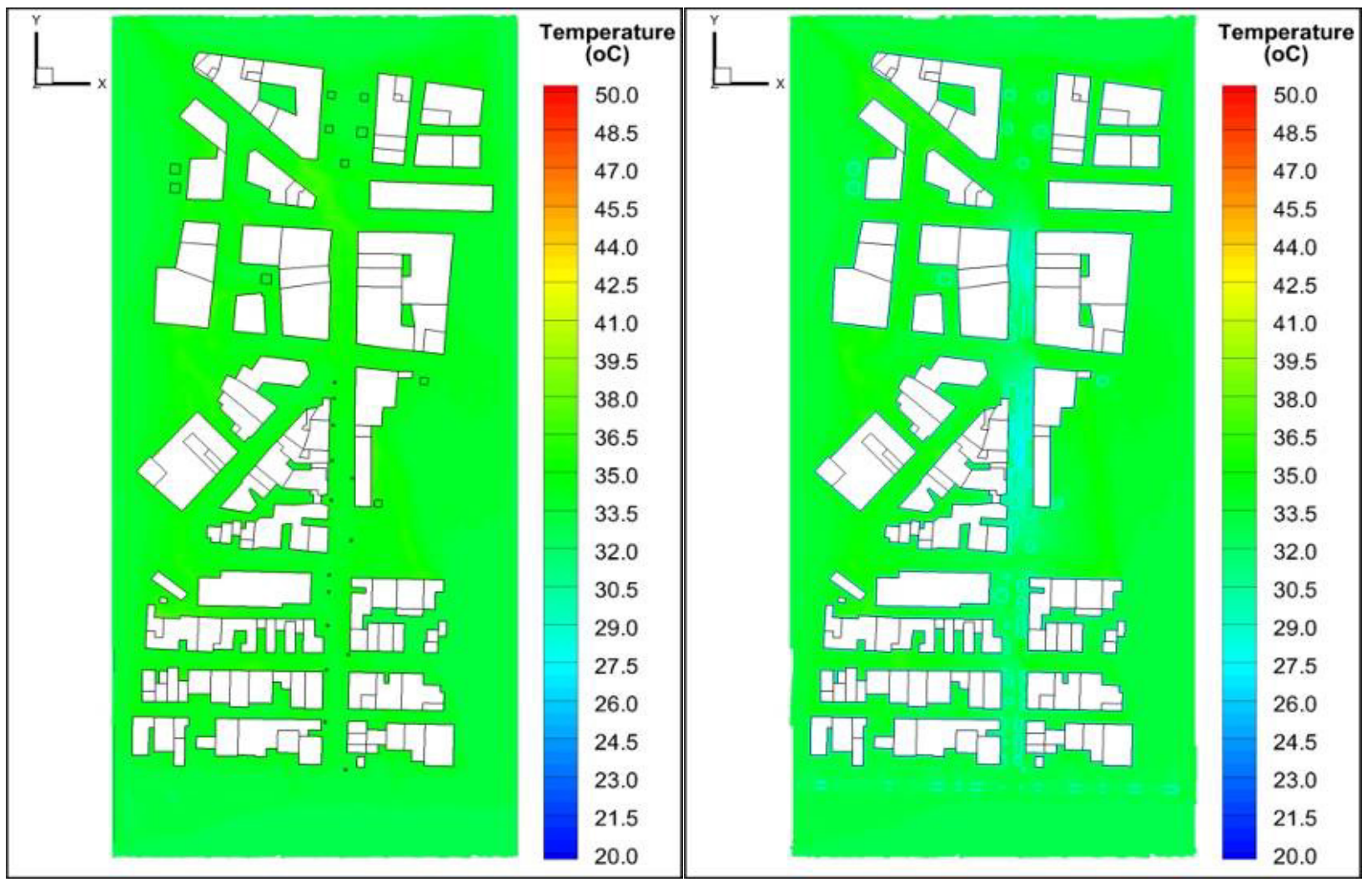

Figure 4. Temperature distribution before and after intervention at 16:00 
In Figures 5 to 7 the developed flow field at $1.8 \mathrm{~m}$ before and after intervention are presented for the hours 6:00, 12:00 and 16:00 of the typical day.
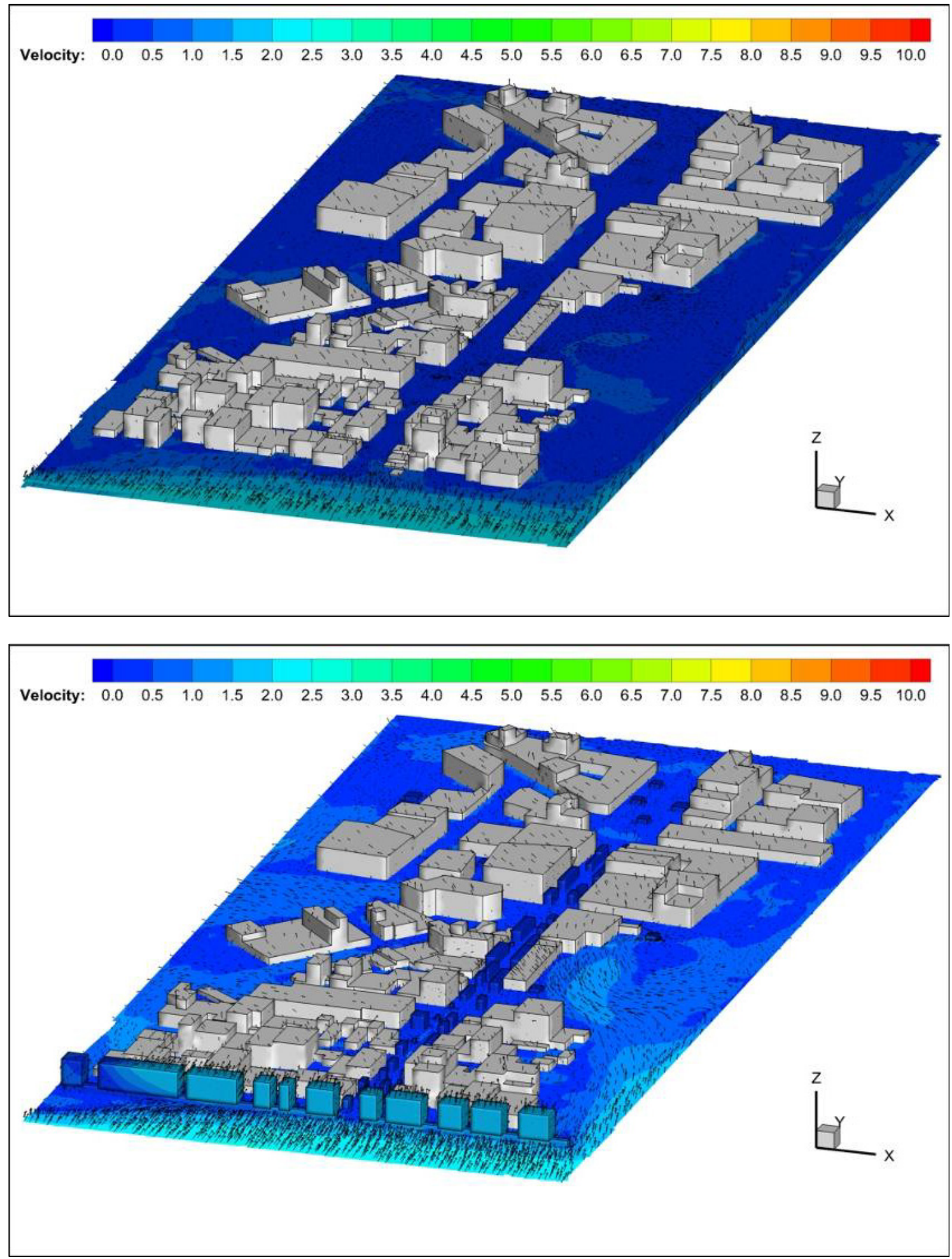

Figure 5. Flow field before and after intervention at 6:00 

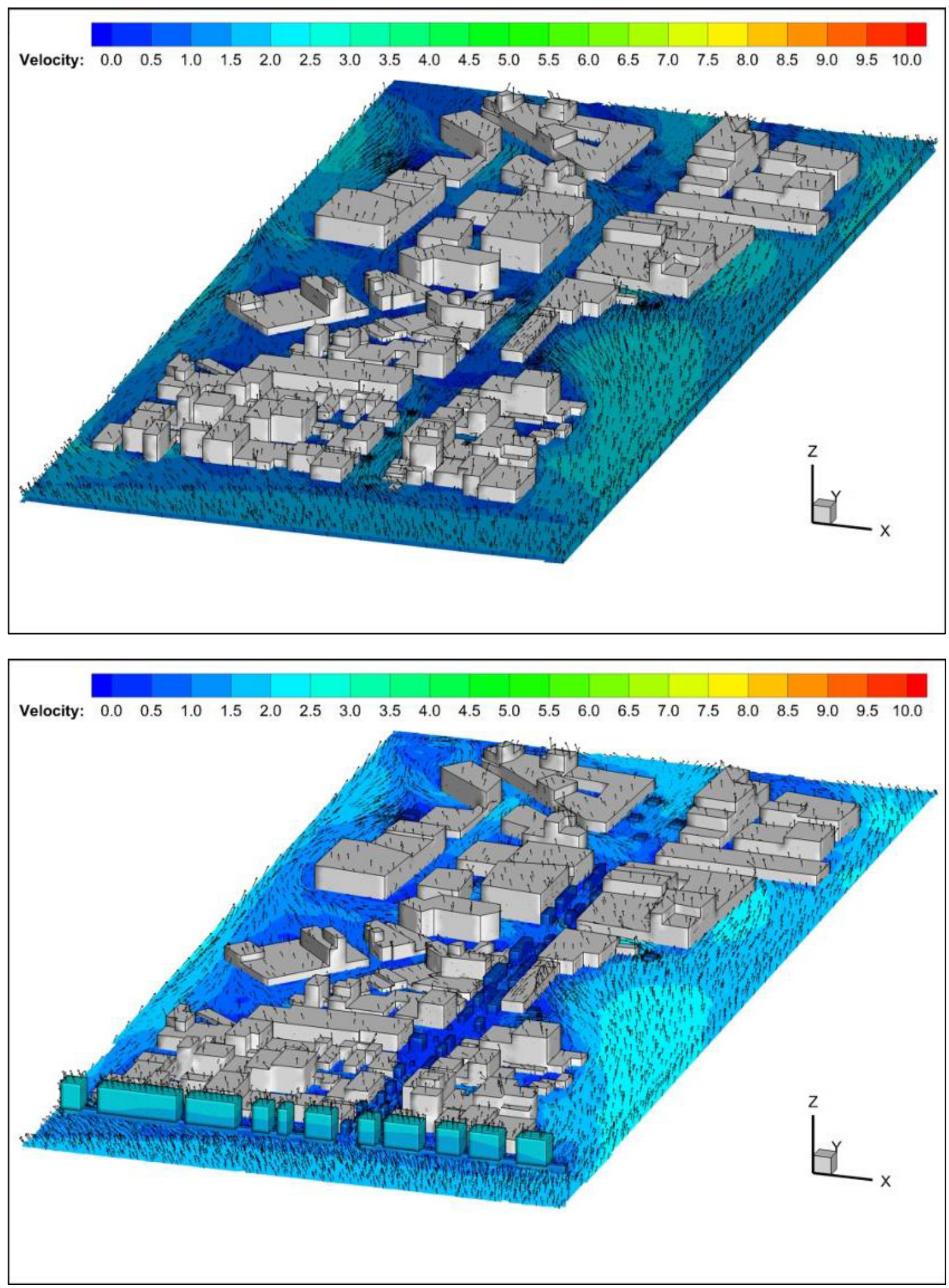

Figure 6. Flow field before and after intervention at 12:00 

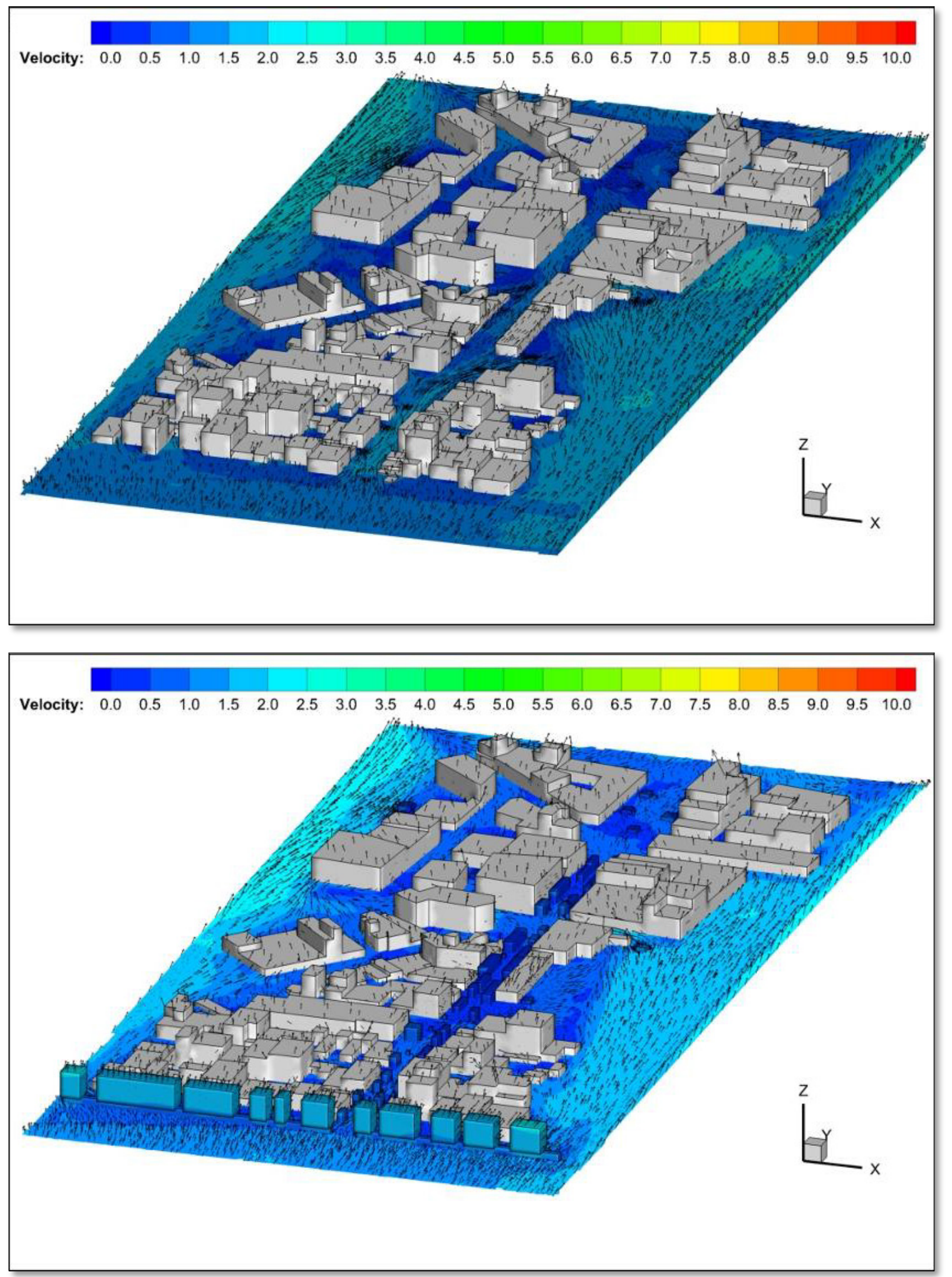

Figure 7. Flow field before and after intervention at 16:00

In Figure 8, the cooling power index (CPI), the cooling degree hours (with base temperature at $26{ }^{\circ} \mathrm{C}$ ) and the spatially average temperature at $1.8 \mathrm{~m}$ along with the cooling degree hours are presented during the examined typical day before and after intervention. 


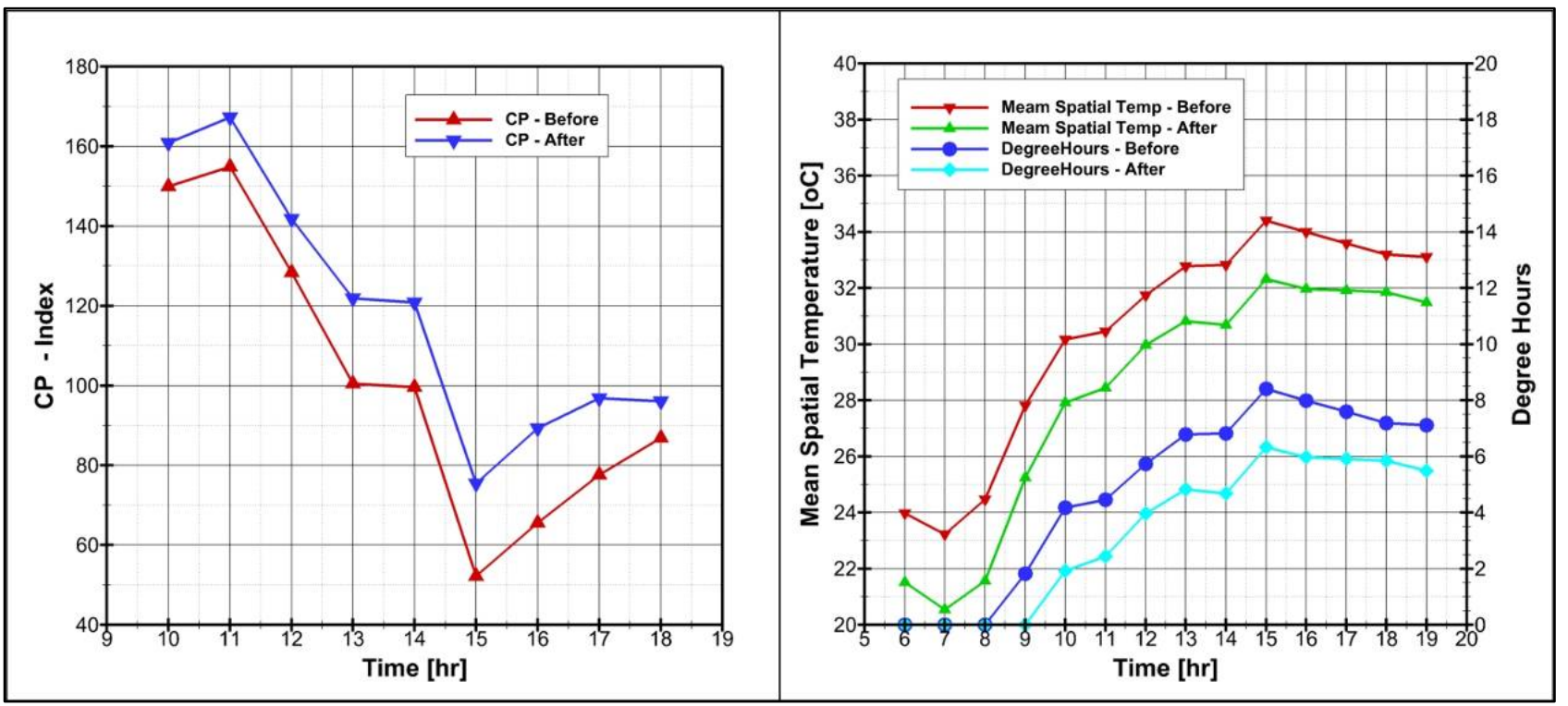

Figure 8. Evolution of cooling power index, average temperature and cooling degree hours during the examined day

The average temperature reduction at the level of $1.8 \mathrm{~m}$ is $1.7^{\circ} \mathrm{C}$, the total cooling degree hours are decreased from 68.07 to 47.39 and the CPI is improved by $17 \%$, but it remains at levels indicating an extremely hot situation. The basic reasons are the low air velocities caused by the trees located in the south boundary of the examined segment which prevents cooling from the sea wind. Nevertheless, the area is characterized by low humidity during the hot hours of the summer. For this reason, the Wet-bulb Globe Temperature (WBGT) is calculated before and after the intervention [21], taking into account the climatic data of the area for the relative humidity.

From the WBGT calculations, an improvement of 5\% was observed, while there is a reduction in time interval in which precautions are required [22] as it is presented in Figure 9. Since the relative humidity remains low and the available shading is expanded, the discomfort feeling is not too intensive for the biggest part of the day.

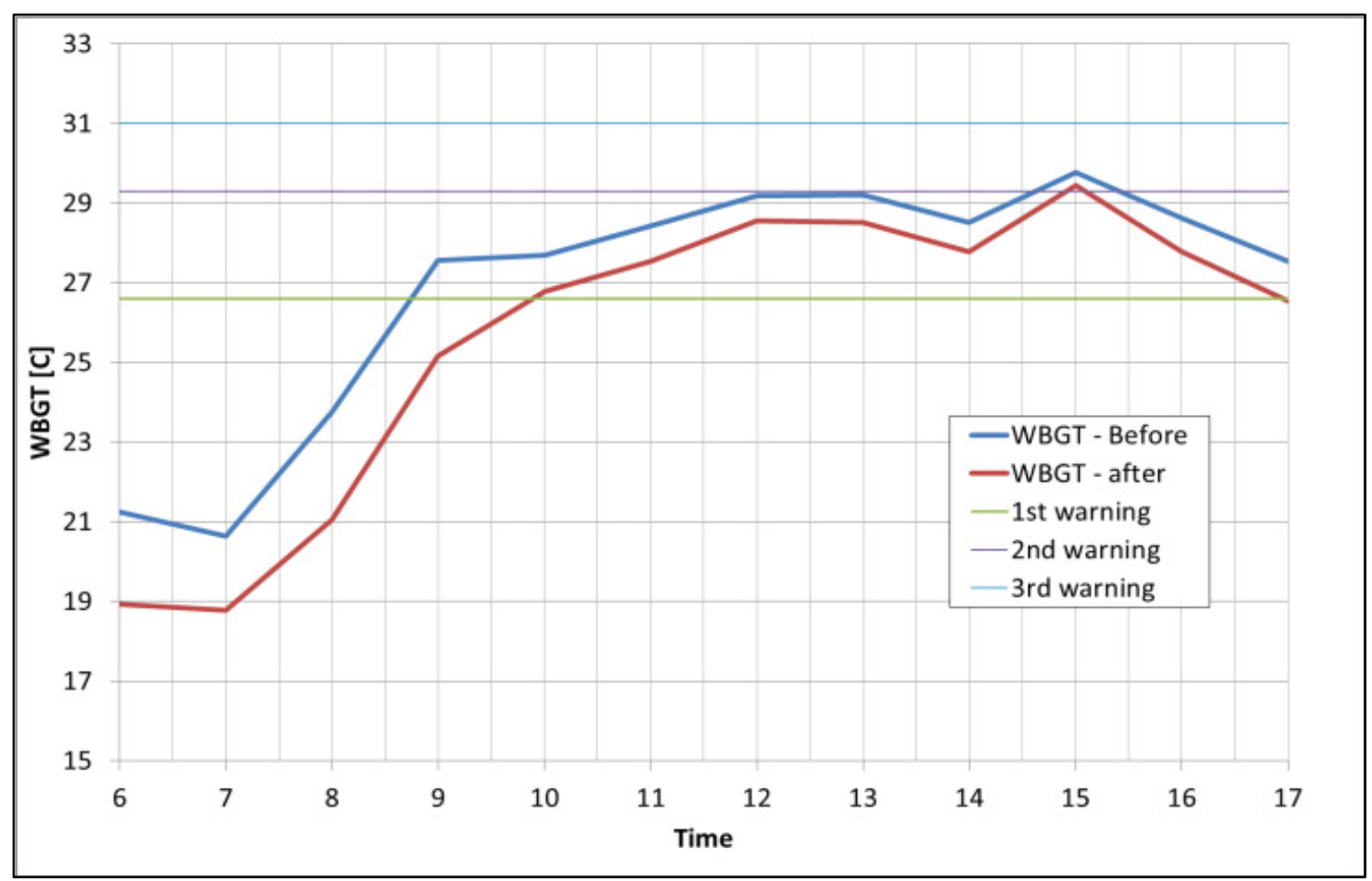

Figure 9. WBGT evolution during the typical day at $1.8 \mathrm{~m}$ before and after the proposed intervention 


\section{Conclusions}

The prediction of the microclimate in an urban segment is a multivariate problem that requires the modeling of various factors. In the present work, a numerical model was developed taking into account not only the geometry and local climatic conditions (wind speed, temperature and solar radiation) but also the materials used, the existence of greenery and water elements and the human activity in the buildings (human presence and operating devices).

According to the calculated thermal comfort indices and the developed temperature and flow fields, the interventions' necessity is fully justified and documented. The proposed interventions which are the replacement of the streets' and pavement cover materials with materials with favorable optical properties and the increase in the green coverage of public spaces demonstrate an improvement in the local microclimate in terms of average temperature and thermal comfort indices. Nevertheless, the arrangement of the trees in the south part of the domain prevents the sea breeze air current and its cooling convection impact, weakening somehow the total effect of the whole proposed intervention.

\section{REFERENCES}

[1] K. Takahashi, H. Yoshida, Y. Tanaka, N. Aotake, F. Wang, Measurement of thermal environment in Kyoto city and its prediction by CFD simulation, Energy and Buildings 36 (2004) 771 .

[2] J. Pospisil, M. Jicha, K. Niachou, M. Santamouris, Computational modelling of airflow in urban street canyon and comparison with measurements, Int. J. of Env. \& Pollution 25(1) (2005) 60.

[3] N. Fintikakis, N. Gaitania, M. Santamouris, M. Assimakopoulos, D.N. Assimakopoulos, M. Fintikaki, G. Albanis, K. Papadimitriou, E. Chryssochoides, K. Katopodi, P. Doumas, 'Bioclimatic design of open public spaces in the historic centre of Tirana, Albania', Sustainable Cities and Society 1 (2011) 54 .

[4] K. Maragkogiannis, D. Kolokotsa, E. Maravelakis, A. Konstantaras, 'Combining terrestrial laser scanning and computational fluiddynamics for the study of the urban thermal environment', 13 (2014), 207.

[5] S. Saneinejad, P. Moonen, J. Carmeliet, 'Coupled CFD, radiation and porous media model for evaluating the micro-climate in an urban environment', Journal of Wind Engineering and Industrial Aerodynamic, 128 (2014), 1.

[6] X. Li, Z. Yu, B. Zhao, Y. Li, 'Numerical analysis of outdoor thermal environment around buildings', Building and Environment 40 (2005) 853.
[7] Y. Ashie, V.T. Ca, T. Asaeda, 'Building canopy model for the analysis of urban climate' Journal of Wind Engineering and Industrial Aerodynamics 81 (1999) 237.

[8] M. Robitu, M. Musy, C. Inard, D. Groleau, Modeling the influence of vegetation and water pond on urban microclimate, Solar Energy 80 (2006) 435.

[9] A.P. Mirzaei, F. Haghighat, 'Approaches to study Urban Heat Island - Abilities and limitations' Building and Environment 45 (2010) 2192.

[10] G.M. Stavrakakis, E. Tzanaki, V.I. Genetzaki,G. Anagnostakis, G. Galetakis, E. Grigorakis, A computational methodology for effective bioclimatic-design applications in the urban environment, Sustainable Cities and Society 4 (2012) 41.

[11] St. Zoras, A. Tsermentselis, P. Kosmopoulos, A. Dimoudi, Evaluation of the application of cool materials in urban spaces: A case study in the center of Florina, Sustainable Cities and Society 13 (2014) 223.

[12] B.E. Launder, D.B. Spalding, The numerical computation of turbulent flows, Computer Methods in Applied Mechanics and Engineering 3 (1974) 269.

[13] J.H. Ferziger, M. Peric, Computational Methods for Fluid Dynamics, Springer, London, 1996.

[14] B.E. Launder, A. Morse, W. Ridi, D.B. Spalding, Prediction of free shear flows - A comparison of the performance of six turbulence models, Procs. Conf. On free turbulent shear flows, Langely Research Center, Hampton, Virginia, 1972.

[15] E.H. Chui, G.D. Raithby, G.D., Computation of radiant heat transfer on a nonorthogonal mesh using the finite-volume method, Numerical Heat Transfer, Part B: Fundamentals: An International Journal of Computation and Methodology, 23 (3) (1993) 269.

[16] G.D. Raithby, Discussion of the finite-volume method for radiation, and its application using 3D unstructured meshes", Numerical Heat Transfer, Part B: Fundamentals: An International Journal of Computation and Methodology, 35(4) (1999) 389.

[17] C. Gromke, R. Buccolieri, D.S. Sabatino, B. Ruck, Dispersion study in a street canyon with tree planting by means of wind tunnel and numerical investigations - Evaluation of CFD data with experimental data, Atmospheric Environment 42 (2008) 8640 .

[18] R.G. Allen, L.S. Pereira, D. Raes, M. Smith, "FAO Irrigation and drainage", FAO 56, 1998.

[19] G. Bergeles G., Wind Turbines, Edd. SIMEON, 1995, Athens, In Greek.

[20] J.A. Duffie, W.A. Beckman, Solar engineering of thermal processes, Wiley, New Jersey, 2006.

[21] V.E. Dimiceli, S.F. Piltz, S.A. Amburn, Estimation of Black Globe Temperature for Calculation of the Wet Bulb Globe Temperature Index, WCECS, S. Francisco, 19-21 Oct., 2011.

[22] Army Technical Bulletin Medical 507 and Air Force Pamphlet 48-152(I) 7 March 2003. 